\title{
The Synthesis of Renewable Hydrocarbons from Vegetable Oil Feedstock in the Presence of Ni-supported Catalysts
}

\author{
Kristaps Malins \\ Riga Technical University, Institute of Applied Chemistry \\ Paula Valdena Str. 3, Riga, Latvia \\ mkrist@inbox.lv or kristaps.malins@rtu.lv
}

\begin{abstract}
The effects of commercial Ni65\%/SiO $2-\mathrm{Al}_{2} \mathrm{O}_{3}$ and prepared $\mathrm{Ni10} \% / \mathrm{SiO}_{2}-\mathrm{Al}_{2} \mathrm{O}_{3}-135 \mathrm{I}$ Ni-supported catalysts and their amount $(1.5-10 \%)$ on hydrocarbon production from rapeseed oil/it fatty acid (RO/RFA, weight ratio 1/1) feedstock were investigated. The textural properties of catalysts were characterized by $\mathrm{N}_{2}$ sorption analysis and active metal loading by XRF. The activity of catalysts was evaluated by minimum oxygen removal reaction time determined from pressure-time profiles at studied operating temperature $340{ }^{\circ} \mathrm{C}$ and initial $\mathrm{H}_{2}$ pressure of 100 bar. GC analysis of obtained hydrocarbon mixtures was used for determination of dominant hydrocarbon $n$-pentadecane, $n$-hexadecane, $n$-heptadecane and $n$-octadecane composition. Both catalyst have proper activity for complete conversion of RO/RFA into marketable hydrocarbon mixture with high yield (76.1\%-83.2\%), calorific value (47.20-47.24 MJ/kg) and energy recovery (ER) (90.7\%-99.1\%) produced at residence time $\sim 35-52 \mathrm{~min}$. $\mathrm{Ni}^{6} \% \mathrm{~S}_{\mathrm{SiO}} \mathrm{S}^{-}$ $\mathrm{Al}_{2} \mathrm{O}_{3}$ has higher activity, but $\mathrm{Ni10} \% / \mathrm{SiO}_{2}-\mathrm{Al}_{2} \mathrm{O}_{3}-135 \mathrm{I}$ deliver elevated yield of hydrocarbons. Both catalysts with different selectivity have a potential for practical application in hydrotreated vegetable oil production processes.
\end{abstract}

Keywords: Nickel, Supported catalysts, Hydrocarbons, Hydrotreatment, Deoxygenation, Vegetable oil.

\section{Introduction}

Long hydrocarbon chains in fatty acid or their glyceride molecules extracted from biomass is perfect feedstock for renewable hydrocarbon production by hydroprocessing. Produced renewable paraffins is sometimes termed as second generation biofuel or hydrotreated vegetable oil or "green diesel" [1]. Unlike biodiesel (fatty acid alkyl esters) produced from triglycerides by alkali catalyzed transesterification reaction with lower alcohols, green diesel is more stable during storage, energy dense and compatible with common diesel engines. Furthermore, renewable hydrocarbons depending on their composition can be used not only as fuel for diesel engines, but also in various industrial areas similarly to hydrocarbons produced from fossil sources. Renewable hydrocarbons produced from vegetable oil or animal fat feedstock do not contain sulphur or aromatic compounds which is difficult to remove by specific and expensive treatment technologies, therefore are more favorable [2]. Production process of hydrotreated vegetable oil, which normally occur simultaneously, was first commercialized by the Neste Oil company (Finland). Following this progress, several other production units have been developed around the world. Hydrotreatment of vegetable or animal oils is catalytic process and can occur by general reaction pathways - hydrogenation, hydrocracking, hydrodeoxygenation, hydrodecarbonylation and hydrodecarboxylation. The hydrotreatment process can be performed in solvent free, water and hydrogen donor, such as, tetralin, decalin and isopropanol medium [3]. Typically, reaction kinetics and impact on the hydrotreating process have been investigated in the presence of some platinum group $\mathrm{Pt}, \mathrm{Pd}, \mathrm{Rh}, \mathrm{Ru}$ and non-noble $\mathrm{Ni}, \mathrm{Mo}, \mathrm{Co}, \mathrm{Cu}, \mathrm{Fe}$ metals supported on $\mathrm{SiO}_{2}, \mathrm{Al}_{2} \mathrm{O}_{3}, \mathrm{ZrO}_{2}$, activated carbon or other materials [2, 4,5]. The metal supported catalysts can be prepared by several impregnation techniques [6]. The reaction pathways mainly depend on particular catalyst support, active metal, its loading and hydroprocessing conditions [5, 7, 8]. Hence, all those factors determine catalyst activity and selectivity. The noble metal catalysts have high performance in the vegetable or animal oil hydrodeoxygenation reactions, however, they are expensive and can be easily deactivated, which limit application in large scale production [4]. Non-noble catalysts are low cost, easy to obtain, recycle and suitable for different catalytic environments. Usually they require relatively high reaction pressure $(5-15 \mathrm{MPa})$ and temperature $\left(300-500{ }^{\circ} \mathrm{C}\right)$, but there are also many reports in the literature, when successful conversion of vegetable or animal oil feedstock was provided under more gentle conditions [6, 9].

Present study is devoted to investigation of vegetable oil feedstock conversion by hydrotreatment into renewable linear hydrocarbons over two different nickel-supported catalysts - commercial $\mathrm{Ni65} \% / \mathrm{SiO}_{2}-\mathrm{Al}_{2} \mathrm{O}_{3}$ and prepared $\mathrm{Ni} 10 \% / \mathrm{SiO}_{2}-\mathrm{Al}_{2} \mathrm{O}_{3}-135 \mathrm{I}$ using incipient wetness impregnation with following calcination and reduction. Rapeseed oil/it fatty acid (RO/RFA, weight ratio 1/1) mixture was utilized as model for hydrotreatment experiments to ensure reaction 
environment similar to industrial, when low cost feedstock with high fatty acid content has been utilized for "green diesel" production.

\section{Experimental \\ 2.1. Materials}

$\mathrm{Ni}\left(\mathrm{NO}_{3}\right)_{2} \cdot 6 \mathrm{H}_{2} \mathrm{O}(99 \%)$ was supplied from Acros organics. $\mathrm{Ni65 \%} / \mathrm{SiO}_{2}-\mathrm{Al}_{2} \mathrm{O}_{3}$ (powder) and catalyst support $\mathrm{SiO}_{2}-$ $\mathrm{Al}_{2} \mathrm{O}_{3}$ (grade 135), Ni powder $(1 \mu, 99.8 \%$ ), derivatization reagent $N$-methyl- $N$-(trimethylsilyl)trifluoroacetamide (MSTFA), analytical standards tricaprin, 1,2,4-butanetriol, methyl heptadecanoate, methyl esters of stearic, palmitic, oleic, linoleic and $\alpha$-linolenic acid, $n$-pentadecane, $n$-hexadecane, $n$-heptadecane and $n$-octadecane for GC analysis were purchased from Sigma-Aldrich. The refined RO delivered from local food grade vegetable oil producer Iecavnieks \& Co was used in experiments. Rapeseed oil fatty acids (RFA) were prepared from RO. The main characteristics of RO and RFA are given in Table 1.

Table 1: The main characteristics of rapeseed oil (RO) and its fatty acids (RFA).

\begin{tabular}{|c|c|c|}
\hline & $\mathrm{RO}$ & RFA \\
\hline Monoglycerides, wt.\% & 0.2 & 0.4 \\
\hline Diglycerides,wt.\% & 0.5 & - \\
\hline Triglycerides, wt. $\%$ & 98.5 & - \\
\hline Saponification value, $\mathrm{mg} \mathrm{KOH} / \mathrm{g}$ & 190.0 & N.A ${ }^{\mathrm{a}}$ \\
\hline Acid value, $\mathrm{mg} \mathrm{KOH} / \mathrm{g}$ & 0.23 & 197.3 \\
\hline Methyl esters, wt.\% & - & - \\
\hline Calorific value, $\mathrm{MJ} / \mathrm{kg}(\mathrm{d} . \mathrm{b})^{\mathrm{b}}$ & 39.70 & 39.49 \\
\hline Water content, wt $\%$ & 0.03 & 0.02 \\
\hline $\mathrm{C} / \mathrm{H}$ & 6.7 & 6.4 \\
\hline $\mathrm{N}, \mathrm{S}$ & & $\leq 0.3^{\mathrm{b}}$ \\
\hline \multicolumn{3}{|c|}{ Fatty acid composition, wt.\% } \\
\hline Palmitic acid (C16:0) & & 4.9 \\
\hline Stearic acid (C18:0) & & 1.1 \\
\hline Oleic acid (C18:1) & & 62.8 \\
\hline Linoleic acid (C18:2) & & 21.9 \\
\hline$\alpha-$ Linolenic acid (C18:3) & & 7.8 \\
\hline Other fatty acids & & 1.4 \\
\hline
\end{tabular}

\footnotetext{
${ }^{\mathrm{a}}$ Not analyzed.

${ }^{\mathrm{b}}$ Method detection limit (MDL).
}

\subsection{Preparation of rapeseed oil fatty acids}

RFA were prepared from $\mathrm{RO}$ in complete saponification reaction with aqueous $\mathrm{NaOH}$ and following treatment with aqueous $\mathrm{HCl}$. $\mathrm{NaCl}, \mathrm{HCl}$, glycerol and other impurities dissolved in water were removed from RFA using separatory funnel. RFA were washed several times with hot distilled water and then dried with rotary evaporator in vacuum (0.9$1.5 \mathrm{kPa}$ ) at $90-100^{\circ} \mathrm{C}$ for $30 \mathrm{~min}$.

\subsection{Preparation of catalysts}

Commercial powdery $\mathrm{SiO}_{2}-\mathrm{Al}_{2} \mathrm{O}_{3}$ (grade 135) was used as catalyst support. Before impregnation the catalyst support was calcined in air at $500^{\circ} \mathrm{C}$ for $6 \mathrm{~h}$. The incipient wetness impregnation method was used for catalyst synthesis. Saturated $\mathrm{Ni}\left(\mathrm{NO}_{3}\right)_{2} \cdot 6 \mathrm{H}_{2} \mathrm{O}$ solution in distilled water was added drop by drop to the support for $1 \mathrm{~h}$ at $70{ }^{\circ} \mathrm{C}$ temperature in closed $250 \mathrm{ml}$ flask while intense stirring $(350 \mathrm{rpm})$ with mechanical mixer. Then the mixture was stirred for additional $1 \mathrm{~h}$ at this temperature. Impregnated catalyst support was dried overnight at room temperature and then calcined in air at $500{ }^{\circ} \mathrm{C}\left(4^{\circ} \mathrm{C} / \mathrm{min}\right.$, hold $\left.4 \mathrm{~h}\right)$.

Calcined catalysts were reduced in Parker Autoclave Engineers batch type stainless steel autoclave-reactor (designed to maximum pressure $343 \mathrm{MPa}$ at $379{ }^{\circ} \mathrm{C}$, volume $500 \mathrm{ml}$ ) at temperature $320^{\circ} \mathrm{C}\left(5 / \mathrm{min}{ }^{\circ} \mathrm{C}\right.$ ) and initial $\mathrm{H}_{2}$ pressure 70 bar for $3 \mathrm{~h}$. Filled and sealed autoclave-reactor was properly purged with $\mathrm{H}_{2}$ (flow rate $10 \mathrm{ml} / \mathrm{s}$ ) for $15 \mathrm{~min}$ to fully eliminate the air atmosphere before reduction. After the reduction process $\mathrm{H}_{2}$ flow $(20 \mathrm{ml} / \mathrm{s}, 20 \mathrm{~min})$ was utilized for removal of water vapors produced from catalyst. 


\subsection{Characterization of catalysts}

$\mathrm{N}_{2}$ sorption analysis was performed with a Quadrasorb SI surface area and pore size analyzer at $-195.85{ }^{\circ} \mathrm{C}$ (Quantachrome Instruments). The specific surface areas were determined using multipoint Brunauer-Emmett-Teller (BET) method based on the adsorption data in the relative pressure $\left(\mathrm{P} / \mathrm{P}_{0}\right)$ range of $0.05-0.30$. The total pore volumes were estimated from the amount of $\mathrm{N}_{2}$ adsorbed at $\mathrm{P} / \mathrm{P}_{0}$ of 0.99 . The maximum relative standard deviation (RSD) of method is $10 \%$.

The active metal loading was determined by Supermini bench-top sequential wavelength dispersive X-ray fluorescence (XRF) spectrometer (Rigaku) in He atmosphere. Powdery mixtures of canalyst support $\mathrm{SiO}_{2}-\mathrm{Al}_{2} \mathrm{O}_{3}$ (grade $135)$ and Ni powder $(1 \mu, 99.8 \%)$ were used as standards for calibration. The maximum RSD of method is $5 \%$.

\subsection{Characterization of rapeseed oil (RO), its fatty acids (RFA) and hydrocarbon samples}

Model feedstock RO, RFA and obtained hydrocarbons in hydrotreating process were analyzed by gas chromatography (GC) system 7890A (Agilent Technologies) equipped with two capillary columns, two flame ionization detectors (FID) and 7683B automatic liquid sampler.

HP-INNOWax $(30 \mathrm{~m} \times 0.25 \mathrm{~mm} \times 0.25 \mu \mathrm{m})$ column was utilized for determination of fatty acid composition according to a modified EN 14103 standard method: carrier gas $\mathrm{H}_{2}$ flow rate $5 \mathrm{ml} / \mathrm{min}$; detector temperature $390{ }^{\circ} \mathrm{C}$; temperature program $-200{ }^{\circ} \mathrm{C}$ (hold $25 \mathrm{~min}$ ). Rapeseed oil methyl ester (RME) sample (99.2\%, prepared from RO and methanol in the presence of alkaline catalyst) was used for calculation of fatty acid composition. It was assumed that RO and RFA have the same fatty acid composition as RME. Methyl heptadecanoate was used as internal standard. Fatty acid methyl ester peaks were identified by comparing retention times of particular standards.

DB5-ht $(15 \mathrm{~m} \times 0.32 \mathrm{~mm} \times 0.10 \mu \mathrm{m})$ column was used for determination of monoglyceride (MG), diglyceride (DG) and triglyceride (TG) content in RO and RFA according to a modified EN14105 standard method: carrier gas $\mathrm{H}_{2}$ flow rate $2 \mathrm{ml} / \mathrm{min}$; detector temperature $390{ }^{\circ} \mathrm{C}$; temperature program $-50{ }^{\circ} \mathrm{C}$ (hold $\left.5 \mathrm{~min}\right) \rightarrow 180{ }^{\circ} \mathrm{C}\left(15^{\circ} \mathrm{C} / \mathrm{min}\right) \rightarrow 230$ ${ }^{\circ} \mathrm{C}\left(7{ }^{\circ} \mathrm{C} / \mathrm{min}\right) \rightarrow 370\left(10^{\circ} \mathrm{C} / \mathrm{min}\right.$, hold $\left.5 \mathrm{~min}\right)$. Derivatization reagent MSTFA and two internal standards tricaprin, 1,2,4-butanetriol were used in GC analysis. The hydrocarbon contents in liquid samples obtained in hydrotreating process were determined in similar manner utilizing tricaprin as internal standard. Analytical standards $n$-pentadecane, $n$-hexadecane, $n$-heptadecane and $n$-octadecane were used for identification of specific hydrocarbon peaks in chromatogram.

Injection volumes of all samples for GC analysis were $1.0 \mu \mathrm{l}$. The maximum RSD of the methods is $2 \%$.

Fourier transform infrared (FT-IR) stretching vibration band in the range of $1750-1700 \mathrm{~cm}^{-1}$ was used for detection of the unconverted carboxyl and carbonyl compounds in hydrocarbon mixture. FT-IR spectrometer PerkinElmer Spectrum 100 equipped with accessory 100T was utilized for analytical procedures. It was experimentally investigated that method detection limit (MDL) for the presence of carboxyl and carbonyl compounds in hydrocarbon mixture is $0.5 \%$ and $1 \%$, respectively.

Water content in liquid samples was determined using METTLER TOLEDO DL39 Karl Fischer coulometer according to the standard method ISO 12937.

Acid value was determined according to the EN 14104 standard method.

Saponification value was determined according to the ISO 3657 standard method.

Calorific value (HHV) was determined using C 200 (IKA) oxygen-bomb calorimeter according to the standard method DIN 51900-3:2005.

C, H, N, S elemental analysis was determined by EA3000 (EuroVector) elemental analyzer.

\subsection{Catalytic tests}

The effects of synthesized $\left(\mathrm{Ni10} \% / \mathrm{SiO}_{2}-\mathrm{Al}_{2} \mathrm{O}_{3}-135 \mathrm{I}\right)$ and commercial $\left(\mathrm{Ni65} \% / \mathrm{SiO}_{2}-\mathrm{Al}_{2} \mathrm{O}_{3}\right)$ catalysts on $\mathrm{RO} / \mathrm{RFA}$ (weight ratio 1/1) conversion into renewable hydrocarbons by hydrotreating process were investigated utilizing initial $\mathrm{H}_{2}$ pressure of $100 \mathrm{bar}$, operating temperature of $340^{\circ} \mathrm{C}$, mixing speed of $300 \mathrm{rpm}$ and different catalyst amount (1.5$10 \%)$.

Each experiment was conducted using $50 \mathrm{~g}$ of RO/RFA (weight ratio 1/1) mixed with catalyst in a batch type stainless steel autoclave-reactor (Parker Autoclave Engineers) used for catalyst reduction. The reactor was equipped with magnetically coupled mechanical mixer (6 blade agitator impeller) and Sentinel Series Controller.

Filled and sealed autoclave-reactor was purged with $\mathrm{H}_{2}$ (flow rate $10 \mathrm{ml} / \mathrm{s}$ ) for $15 \mathrm{~min}$ to fully eliminate air atmosphere from the pressure vessel. Then $\mathrm{H}_{2}$ pressure was increased to necessary initial value.

Hydrogenation of $-\mathrm{C}=\mathrm{C}-$ bond and general oxygen removal reactions (hydrodeoxygenation, hydrodecarboxylation and hydrodecarbonylation) of vegetable oil or fatty acids are complicated process and it consume $\mathrm{H}_{2}$ in significant amount [1]. Oxygen removal step occurs at significantly higher temperature than hydrogenation and can be identified 
by obvious change of pressure in pressure-time profiles of the hydrotreating process. Change of the pressure value from the maximum to minimum at operating temperature during hydrodeoxygenation, hydrodecarboxylation and hydrodecarbonylation step was used for estimation of minimum oxygen removal reaction time (Table 2). It is time when highest $\mathrm{H}_{2}$ consumption was observed and largest part of RO/RFA converts into hydrocarbons and particular amount of their intermediates. Despite high repeatability of catalytic test results this parameter determined from pressure-time profiles is not absolute and serves for estimation of catalyst activity and overall residence time. After the minimum oxygen removal reaction time + additional 25 min the hydrotreating process was terminated by switching of the mixer and rapid cooling of pressure vessel with air fan. The 95\%-97\% of hydrocarbons and other substances produced in the process was easily separated from reaction mixture by centrifugation at $3000 \mathrm{rpm}$ for $3 \mathrm{~min}$. The rest of products were extracted by acetone. The acetone was recovered by distillation using rotary evaporator. After acetone recovery thin layer of the samples in Petri dish was dried at $120^{\circ} \mathrm{C}$ for $20 \mathrm{~min}$ to remove water produced in hydrotreating process. The mixture of samples recovered by both methods was used for determination of hydrocarbon yields and other characterizations.

\subsection{Calculations}

Each experiment was repeated twice. Absolute experimental values were expressed as arithmetic mean from the two independently repeated experiments. A third independent experiment was performed in cases when previous two experimental values differed more than 5\%. The average result of experiment with maximum RSD 3.0\% was determined using two closest experimental values. The absolute values of all quantitative analysis data were obtained in similar manner.

Energy recovery (ER) calculated by Eq. (1) is an important parameter to evaluate the influence of experimental conditions on overall conversion of feedstock RO/RFA mixture into desired product - hydrocarbons.

$$
\mathbf{E R}(\%)=\frac{\mathbf{C V}_{\mathbf{P}} \cdot \mathbf{Y}_{\mathbf{P}}}{\mathbf{C V}_{\mathbf{F}}}
$$

where $\mathrm{CV}_{\mathrm{P}}$ and $\mathrm{CV}_{\mathrm{F}}$ are calorific values of product and feedstock, respectively. $\mathrm{Y}_{\mathrm{P}}(\%)$ is overall yield of products calculated by Eq. (2).

$$
\mathbf{Y}_{\mathbf{P}}(\%)=\frac{\mathbf{m}_{\mathbf{p}}}{\mathbf{m}_{\mathbf{f}}} \cdot \mathbf{1 0 0}
$$

where $\mathrm{m}_{\mathrm{P}}$ is the mass of product and $\mathrm{m}_{\mathrm{F}}$ is the mass of feedstock.

$\mathrm{Y}_{\mathrm{CH}}(\%)$ (Eq. (3)) is the yield of the dominant hydrocarbons ( $n$-pentadecane, $n$-hexadecane, $n$-heptadecane and $n$ octadecane) produced in the hydrotreating process.

$$
\mathbf{Y}_{\mathbf{C H}}(\%)=\frac{\mathbf{Y}_{\mathrm{P}} \cdot \mathbf{C}_{\mathrm{CH}}}{100}
$$

where $\mathrm{C}_{\mathrm{CH}}$ is $n$-pentadecane, $n$-hexadecane, $n$-heptadecane and $n$-octadecane content determined by GC.

\section{Results and discussion}

\subsection{The effect of catalyst type and amount on hydrocarbon production from rapeseed oil and it fatty acid feedstock}

The average molecular size of feedstock RO, RFA and partially converted intermediates in hydrotreating process are roughly $\leq 4 \mathrm{~nm}$ [10]. Both catalysts utilized for catalytic tests have high specific surface area, total pore volume and sufficient average pore diameter (Table 2). Commercial catalyst $\mathrm{Ni65 \%} / \mathrm{SiO}_{2}-\mathrm{Al}_{2} \mathrm{O}_{3}$ showed significantly higher activity than prepared $\mathrm{Ni10 \%} / \mathrm{SiO}_{2}-\mathrm{Al}_{2} \mathrm{O}_{3}$-135I. Catalytic performance depends on many characterizations of Ni-supported catalysts, but active metal loading is one of the key factors. Typically, enough high active metal loading ensures high activity of supported catalysts [5]. The minimum time necessary for main oxygen removal reactions (hydrodeoxygenation, hydrodecarboxylation and hydrodecarbonylation) is $\sim 7$ times shorter for $\mathrm{Ni65} \% / \mathrm{SiO}_{2}-\mathrm{Al}_{2} \mathrm{O}_{3}$ in comparison to $\mathrm{Ni10 \%} / \mathrm{SiO}_{2}-\mathrm{Al}_{2} \mathrm{O}_{3}-135 \mathrm{I}$ when identical catalyst amount $(5 \%)$ was used in the process (Table 2). However, overall residence time of hydrocarbon production in the presence of catalyst with low active metal loading can be reduced with increase of catalyst amount. 
Table 2: Textural properties, the effect of Ni-supported catalyst type and their amount on minimum oxygen removal reaction time of rapeseed oil and its fatty acid (RO/RFA, weight ratio 1/1) feedstock conversion into hydrocarbons by hydrotreatment.

\begin{tabular}{|c|c|c|c|c|c|c|}
\hline & $\begin{array}{l}\mathrm{Ni}^{\mathrm{a}} \text {, } \\
\text { wt. } \%\end{array}$ & $\begin{array}{l}\mathrm{S}_{\mathrm{BET}}^{\mathrm{b}} \\
\mathrm{m}^{2} / \mathrm{g}\end{array}$ & $\begin{array}{c}\mathrm{V}^{\mathrm{c}} \\
\mathrm{cm}^{3} / \mathrm{g}\end{array}$ & $\begin{array}{l}\mathrm{D}^{\mathrm{d}}, \\
\mathrm{nm}\end{array}$ & $\begin{array}{l}\text { Minimum oxygen removal } \\
\text { reaction time } e^{\mathrm{e}}, \min ( \pm 3 \%)\end{array}$ & $\begin{array}{c}\text { Catalyst } \\
\text { amount, \% }\end{array}$ \\
\hline $\begin{array}{l}\mathrm{Ni65 \%} / \mathrm{SiO}_{2}-\mathrm{Al}_{2} \mathrm{O}_{3} \\
\text { Commercial }\end{array}$ & 64.7 & 165 & 0.25 & 6.0 & $\begin{array}{l}17.0 \\
16.5 \\
10.3\end{array}$ & $\begin{array}{l}1.5 \\
2.0 \\
5.0\end{array}$ \\
\hline $\begin{array}{c}\mathrm{Ni} 10 \% / \mathrm{SiO}_{2}-\mathrm{Al}_{2} \mathrm{O}_{3}-135 \mathrm{I} \\
\text { Prepared }\end{array}$ & 9.4 & 412 & 0.51 & 5.0 & $\begin{array}{l}74.2 \\
26.8\end{array}$ & $\begin{array}{c}5 \\
10\end{array}$ \\
\hline
\end{tabular}

${ }^{\mathrm{e}}$ Main reactions - hydrodeoxygenation, hydrodecarboxylation and hydrodecarbonylation; Determined from the pressure-time profiles of hydrotreating process.

The mass fraction of active metal $\mathrm{Ni}$ in reaction mixture is close for both catalysts when catalyst amount $10 \%$ of $\mathrm{Ni} 10 \% / \mathrm{SiO}_{2}-\mathrm{Al}_{2} \mathrm{O}_{3}-135 \mathrm{I}$ and $1.5 \%$ of $\mathrm{Ni65} \% / \mathrm{SiO}_{2}-\mathrm{Al}_{2} \mathrm{O}_{3}$ are being utilized in process. Under these experimental conditions minimum oxygen removal reaction time over prepared catalyst was only by 9.8 min $( \pm 3 \%)$ longer in comparison with $\mathrm{Ni65 \%} / \mathrm{SiO}_{2}-\mathrm{Al}_{2} \mathrm{O}_{3}$. This observation confirms, that mass fraction of active metal $\mathrm{Ni}$ provided by amount of supported catalyst in the reaction mixture have significant impact on reaction rate and conversion. Commercial catalyst $\mathrm{Ni65 \%} / \mathrm{SiO}_{2}-\mathrm{Al}_{2} \mathrm{O}_{3}$ ensures high RO/RFA conversion at short residence time using low catalyst amounts (Fig.1.). On the other hand, overall yield of all products including dominant hydrocarbons ( $n$-pentadecane, $n$ hexadecane, $n$-heptadecane and $n$-octadecane) is higher for $\mathrm{Ni10} \% / \mathrm{SiO}_{2}-\mathrm{Al}_{2} \mathrm{O}_{3}-135 \mathrm{I}$.

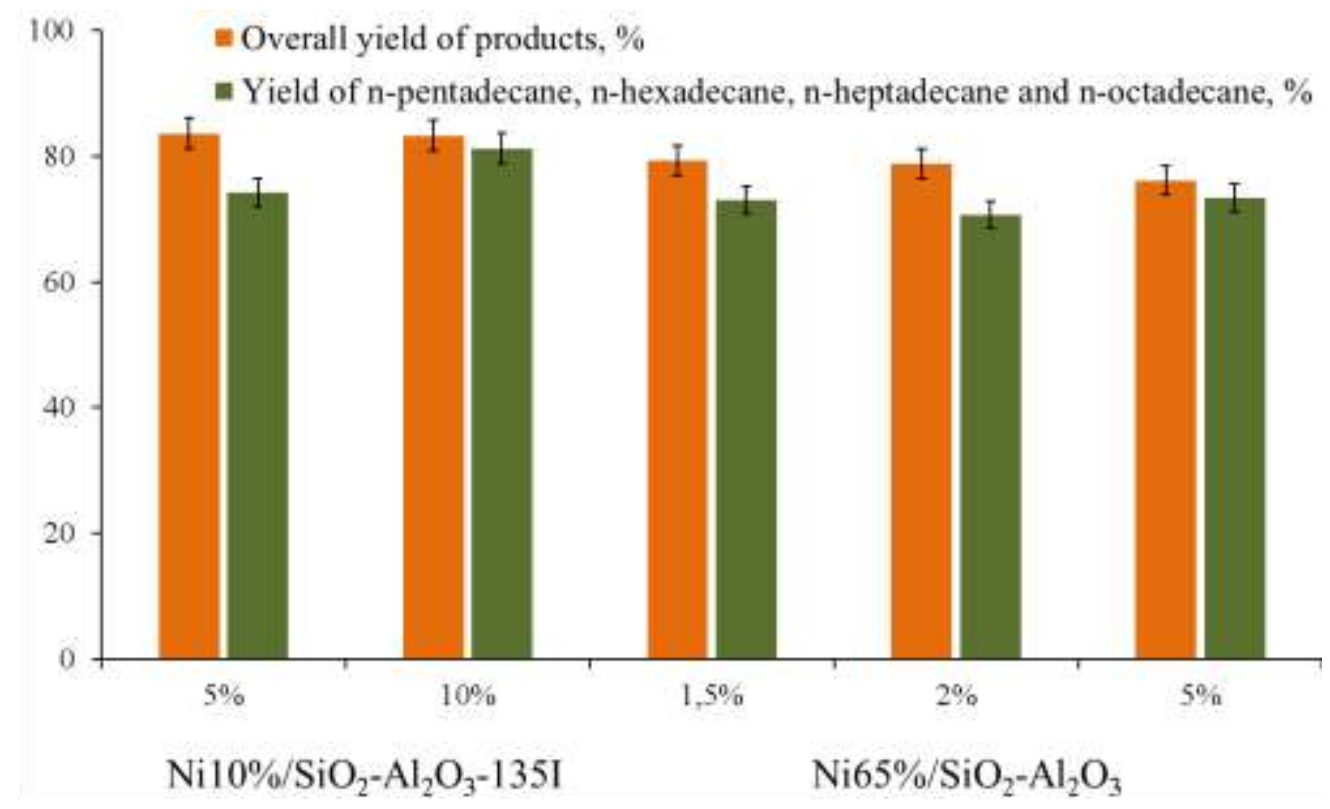

Fig. 1: The effect of catalyst type and amount on product yields. Hydrotreating conditions: operating temperature $340{ }^{\circ} \mathrm{C}$, initial $\mathrm{H}_{2}$ pressure 100 bar, mixing speed $300 \mathrm{rpm}$, overall residence time (minimum oxygen removal reaction time from Table $2+25$ $\min )$.

Overall yield of products extracted from reaction mixture after hydrotreating process in the presence of $\mathrm{Ni} 10 \% / \mathrm{SiO}_{2}-\mathrm{Al}_{2} \mathrm{O}_{3}-135 \mathrm{I}$ and $\mathrm{Ni65 \%} / \mathrm{SiO}_{2}-\mathrm{Al}_{2} \mathrm{O}_{3}$ was in range of $(83.2 \%-83.6 \%)$ and $(76.1 \%-79.2 \%)$, respectively. Furthermore, highest yield of dominant hydrocarbons (73.4\%-81.2\%) was achieved utilizing maximum amount of studied catalysts. Highest overall yield of all products and four dominant hydrocarbons in mixture obtained in the presence of $\mathrm{Ni} 10 \% / \mathrm{SiO}_{2}-\mathrm{Al}_{2} \mathrm{O}_{3}-135 \mathrm{I}$ was $\sim 7 \%$ and $\sim 8 \%$ higher in comparison to $\mathrm{Ni65} \% / \mathrm{SiO}_{2}-\mathrm{Al}_{2} \mathrm{O}_{3}$. Hence, energy 
recovery also was $\sim 9 \%$ higher and reached $99.1 \%$. It can be explained that $\mathrm{Ni10 \% /} / \mathrm{SiO}_{2}-\mathrm{Al}_{2} \mathrm{O}_{3}-135 \mathrm{I}$ gave hydrocarbon mixture with high $n$-octadecane content $(58.4 \%)$ produced in hydrodeoxygenation reactions (Fig. 2.). The mixture contains also $n$-heptadecane in large quantity and it was produced by other two oxygen removal pathways hydrodecarboxylation and hydrodecarbonylation [1]. Catalytic transformation of feedstock containing mostly $\mathrm{C}_{18}$ fatty acids (Table 1) into $n$-octadecane instead of $n$-heptadecane increases overall hydrocarbon yield and ER due to it has $5.8 \%$ higher molecular weight than later one. Opposite to prepared catalyst $\mathrm{Ni65 \%} / \mathrm{SiO}_{2}-\mathrm{Al}_{2} \mathrm{O}_{3}$ produces mostly $n$ heptadecane. The $n$-heptadecane content reached $82 \%$ using the highest catalyst amount. Furthermore, slightly elevated $n$-pentadecane and $n$-hexadecane content in the obtained hydrocarbon mixture was observed using commercial catalyst. Most rather decrease of overall yield in the presence of $\mathrm{Ni65 \%} / \mathrm{SiO}_{2}-\mathrm{Al}_{2} \mathrm{O}_{3}$ increases $\mathrm{C}_{15}-\mathrm{C}_{16}$ content. Seems that under studied experimental conditions $\mathrm{Ni65 \%} / \mathrm{SiO}_{2}-\mathrm{Al}_{2} \mathrm{O}_{3}$ promotes also slight cleavage of $-\mathrm{C}-\mathrm{C}-$ hydrocarbon bond and produce aliphatic compounds with lower molecular weight than $\mathrm{C}_{17}-\mathrm{C}_{18}$. Some light hydrocarbons produced in the process might be lost during hydrocarbon extraction procedures. It reduces overall yield of products and ER. Marketable hydrocarbon mixtures without evidence of dissolved carboxyl and carbonyl compounds (FT-IR, detection limit less than 0.5-1.0\%) were obtained using only maximum catalyst amounts. The mixtures have high calorific value (47.20-47.24 $\mathrm{MJ} / \mathrm{kg}$ ) and dominant hydrocarbon content (96.4-97.6\%). The rest is hydrocarbons with wide range of molecular weight (analyzed by GC) produced from other fatty acids in oxygen removal reactions and by cleavage of $-\mathrm{C}-\mathrm{C}-$ hydrocarbon bond. Other samples with similar calorific value contain particular amount of partially converted oxygen containing intermediates. Both catalysts have different selectivity and activity. $\mathrm{Ni65 \%} / \mathrm{SiO}_{2}-\mathrm{Al}_{2} \mathrm{O}_{3}$ has higher activity, but $\mathrm{Ni} 10 \% / \mathrm{SiO}_{2}-\mathrm{Al}_{2} \mathrm{O}_{3}-135 \mathrm{I}$ better selectivity to reach maximum overall yield of marketable product and ER. Investigated advantages of both catalysts are important for consideration of their utilization potential in hydrocarbon production from various fatty acid containing feedstock.

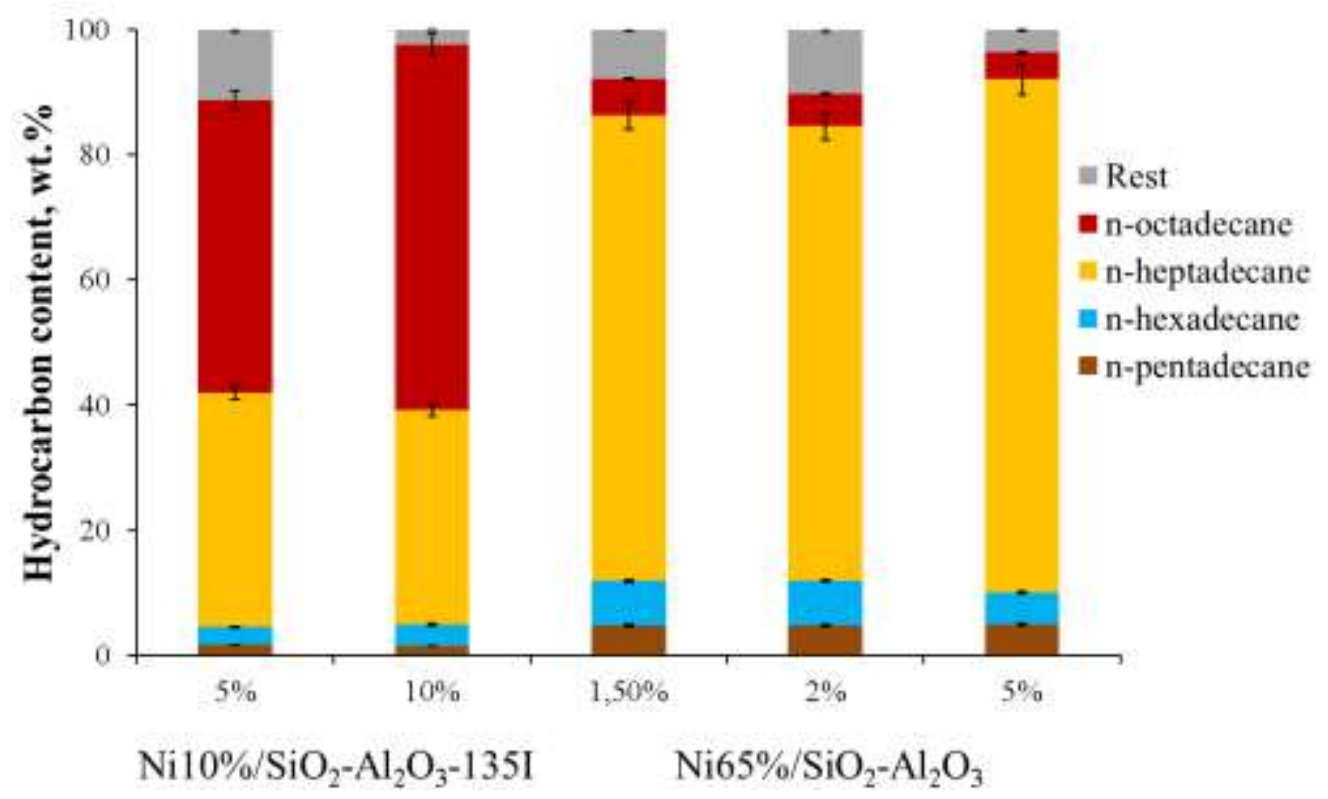

Fig. 2: The effect of catalyst type and amount on dominant hydrocarbon composition. Hydrotreating conditions: operating temperature $340{ }^{\circ} \mathrm{C}$, initial $\mathrm{H}_{2}$ pressure 100 bar, mixing speed $300 \mathrm{rpm}$, overall residence time (minimum oxygen removal reaction time from Table $2+25 \mathrm{~min}$ ).

\section{Conclusions}

Commercial Ni supported catalyst $\mathrm{Ni65 \%} / \mathrm{SiO}_{2}-\mathrm{Al}_{2} \mathrm{O}_{3}$ has high activity on hydrocarbon production from $\mathrm{RO} / \mathrm{RFA}$ (weight ratio 1/1) mixture by hydroprocessing. Under studied experimental conditions high yield (76.1\%) and ER $(90.7 \%)$ of marketable hydrocarbon mixture with $96.4 \%$ of dominant $\mathrm{C}_{15}-\mathrm{C}_{18}$ content $(82 \% n$-heptadecane) was obtained at short overall residence time $(\sim 35 \mathrm{~min})$ using $5 \%$ of catalyst. $\mathrm{Ni10 \%} / \mathrm{SiO}_{2}-\mathrm{Al}_{2} \mathrm{O}_{3}-135 \mathrm{I}$ is less active, but opposite to commercial catalyst it produces high $n$-octadecane content $(58.4 \%)$, which forms in deoxygenation reactions and increases overall yield of hydrocarbons up to $83.2 \%$ and ER up to $99.1 \%$ using $10 \%$ of catalyst amount in $~ 52 \mathrm{~min}$ of hydrotreating process. Studied catalysts have selectivity towards specific hydrocarbons, which is one of the most important feature for consideration of their practical application potential in hydroprocessing of vegetable or animal oil feedstock. 


\section{Acknowledgments}

This work has been supported by the European Regional Development Fund within the Activity 1.1.1.2 "Postdoctoral Research Aid" of the Specific Aid Objective 1.1.1 "To increase the research and innovative capacity of scientific institutions of Latvia and the ability to attract external financing, investing in human resources and infrastructure" of the Operational Programme "Growth and Employment" (No. 1.1.1.2/VIAA/1/16/031).

\section{References}

[1] J. K. Satyarthi, T. Chiranjeevi, D. T. Gokak, P. S. Viswanathan, "An overview of catalytic conversion of vegetable oils/fats into middle distillates," Catal. Sci. Technol., vol. 3, pp. 70-80, 2013.

[2] A. Galadima, O. Muraza, "Catalytic upgrading of vegetable oils into jet fuels range hydrocarbons using heterogeneous catalysts: A review," Ind. Eng. Chem., vol. 29, pp.12-23, 2015.

[3] Y. Yang, Q. Wang, H. Chen, X. Zhang, "Enhancing selective hydroconversion of C18 fatty acids into hydrocarbons by hydrogen-donors," Fuel, vol. 133, pp. 241-244, 2014.

[4] S. Chen, G. Zhou. C. Miao, "Green and renewable bio-diesel produce from oil hydrodeoxygenation: Strategies for catalyst development and mechanism," Renew. Sust. Energ. Rev., vol. 101, pp. 568-589, 2019.

[5] M. Gousi, C. Andriopoulou, K. Bourikas, S. Ladas, M. Sotiriou, C. Kordulis, A. Lycourghiotis, "Green diesel production over nickel-alumina co-precipitated catalysts," Appl. Catal., A., vol. 536, pp. 45-56, 2017.

[6] C. Kordulis, K. Bourikas, M. Gousi, E. Kordouli, A. Lycourghiotis, "Development of nickel based catalysts for the transformation of natural triglycerides and related compounds into green diesel: a critical review," Appl. Catal., B., vol. 181, pp. 156-196,. 2016.

[7] P. Kumar, S. R. Yenumala, S. K. Maity, D. Shee, "Kinetics of hydrodeoxygenation of stearic acid using supported nickel catalysts: Effects of supports," Appl. Catal., A., vol 471, pp. 28-38.

[8] B. P. Pattanaik, R. D. Misra, "Effect of reaction pathway and operating parameters on the deoxygenation of vegetable oils to produce diesel range hydrocarbon fuels: A review," Renew. Sust. Energ. Rev., vol 73, pp. 545557, 2017.

[9] E. Kordouli, B. Pawelec, K. Bourikas, C. Kordulis, J. L. G. Fierro, A. Lycourghiotis, "Mo promoted Ni-Al2O3 co-precipitated catalysts for green diesel production," Appl. Catal., B., vol. 229, pp. 139-154, 2018.

[10] K. Malins, V. Kampars, J. Brinks, I. Neibolte, R. Murnieks, "Synthesis of activated carbon based heterogenous acid catalyst for biodiesel preparation," Appl. Catal., B., vol. 176-177, pp. 553-558, 2015. 